\title{
Fatty Acid Transport and Incorporation into Human Erythrocytes In Vitro*
}

\author{
Richard K. Donabedian and Arthur Karmen $\dagger$ \\ (From the Department of Radiological Science, The Johns Hopkins Medical Institutions, \\ Baltimore, Md., and the Collaborative Studies Section, National Heart Institute, \\ Bethesda, Md.)
}

\begin{abstract}
Summary. When human erythrocytes were incubated in vitro with ${ }^{14} \mathrm{C}$-labeled free fatty acids bound to serum albumin, labeled fatty acids were incorporated into erythrocyte triglycerides and phospholipids. The first step in this reaction was the transfer of free fatty acids from the albumin to the cells. This transfer was rapid and reversible. The acids were distributed between albumin and cells according to the relative quantities of albumin and cells present. Each acid had a different distribution coefficient. At equilibrium, relatively larger fractions of the stearic and palmitic acids and smaller fractions of the oleic and linoleic were associated with the cells. All these fatty acids were then slowly incorporated into phospholipids and triglycerides. The rate of incorporation of each was a function of its concentration in the cells, but larger fractions of the oleic and linoleic were incorporated than of the stearic, palmitic, myristic, or lauric. The two processes of transfer and incorporation thus had almost opposite selectivities for the different fatty acids. As a result, the fatty acids incorporated into triglycerides and phospholipids resembled in composition the fatty acids on the albumin except for moderately less stearic acid.
\end{abstract}

\section{Introduction}

Farquhar and Ahrens (1) have observed that after a change in the fatty acid composition of the diet, the fatty acid composition of human erythrocyte (RBC) phospholipids changed. An increase or decrease in the linoleic acid content of the diet produced a similar but smaller change in the RBC composition. The change was complete and a new stable composition was reached after only 4 to 6 weeks on the new diet. Because this time was short compared to the average life-span of the RBC, the change in composition could not be explained entirely by the incorporation of different fatty acids into maturing $\mathrm{RBC}$ in the bone marrow. It

\footnotetext{
* Submitted for publication May 24, 1966; accepted March 10, 1967.

Supported by U. S. Public Health Service grant GM 11535.

† Address requests for reprints to Dr. Arthur Karmen, Dept. of Radiological Science, The Johns Hopkins Medical Institutions, 615 N. Wolfe St., Baltimore, Md. 21205.
}

seemed more likely that the fatty acids of mature, circulating $\mathrm{RBC}$ were being replaced. A possible mechanism might be the replacement of the fatty acids of the RBC phospholipids with fatty acids from the plasma free fatty acid pool. Oliveira and Vaughan (2) and Mulder, De Gier, and Van Deenen $(3,4)$ have observed that $\mathrm{RBC}$ in vitro can incorporate FFA into cellular phospholipids. This paper describes a study of this in vitro reaction. It was designed particularly to provide more information about the selectivity of human RBC for different long chain fatty acids, which may be one of the determinants of RBC fatty acid composition.

\section{Methods}

Red blood cells. Freshly drawn blood was mixed with heparin and centrifuged at $100,000 \mathrm{~g}$ for 30 minutes. The plasma and the upper third of the cell column were removed. The cells were then resuspended in $3 \mathrm{vol}$ of isotonic saline and recentrifuged, and the supernatant and top of the column were again removed. The leu- 
kocyte count of the remainder varied between 400 and 800 per $\mathrm{mm}^{3}$ packed RBC.

Fatty acids. Fatty acids labeled with ${ }^{14} \mathrm{C}$ in the carboxyl carbon were purchased. ${ }^{1}$ Specific activities were between 12 and $38 \mathrm{mc}$ per mmole. For removal of any labeled short chain acid impurities, each fatty acid was dissolved in $10 \mathrm{ml}$ hexane: glacial acetic acid $(1: 1$, vol/ vol), $1 \mathrm{ml}$ water was added, and the aqueous phase was removed and discarded (5). The hexane phase was then washed with water to remove any remaining acetic acid and then shaken with an equal volume of $0.1 \mathrm{~N}$ potassium hydroxide in $50 \%$ ethanol (6) to separate the fatty acids from any fatty acid esters present. The ethanol$\mathrm{KOH}$ phase, which contained the fatty acids, was separated, acidified with $1 \mathrm{~N} \mathrm{H}_{2} \mathrm{SO}_{4}$, and extracted three times with hexane. Gas-liquid chromatography (GLC) of the methyl esters prepared from each acid revealed that the radioactivity emerged from the column with the same retention time as the corresponding unlabeled ester. The relationship between radioactivity injected into the GLC column and the peak area on the GLC record of radioactivity was the same for each of the fatty acids and equal to that of the standard. These fatty acids were therefore pure within the limits of these methods.

Human serum albumin was obtained commercially. ${ }^{2}$ As supplied, it contained $0.3 \mu$ mole fatty acid per $50 \mathrm{mg}$ albumin by GLC analysis using heptadecanoic acid as internal standard (7). [Lauric $(12: 0)=2 \%$; myristic $(14: 0)=3 \%$; palmitic $(16: 0)=28 \%$; stearic $(18: 0)=$ $5 \%$; oleic $(18: 1)=36 \% ;$ linoleic $(18: 2)=19 \%$; arachidonic $(20: 4)=7 \%$.] The purified ${ }^{14} \mathrm{C}$-labeled fatty acids were bound to the albumin by dissolving them in $2 \mathrm{ml}$ of heptane and then layering the heptane over $20 \mathrm{ml}$ of a solution containing albumin in buffer $(0.061$ $\mathrm{M}$ in $\mathrm{PO}_{4}, 0.077 \mathrm{M} \mathrm{NaCl}, \mathrm{pH} \mathrm{7.4)} \mathrm{(8)} \mathrm{in} \mathrm{a} \mathrm{stoppered}$ culture tube. The tube was then flushed with nitrogen and sealed, and the contents were allowed to equilibrate for 24 hours. More than $90 \%$ of the ${ }^{14} \mathrm{C}$ was transferred to the albumin phase by this procedure. The heptane phase was then removed and the ${ }^{14} \mathrm{C}$ fatty acids therein were recovered. (We chose this method of binding fatty acids to albumin in preference to the simpler method of adding the albumin to a dilute aqueous solution of the fatty acid salt to be certain that all the labeled fatty acid was bound to albumin and not in suspension as particles of undissolved soap.) The same method was used to transfer unlabeled fatty acids to albumin when the quantity or the composition of the FFA on the albumin was varied. Cellulose strip electrophoresis of the albumin prepared by this method revealed a homogeneous band identical to that from the original albumin. Liquid scintillation counting of sections of the electrophoretic strip revealed no significant radioactivity except in the albumin band.

Incubation, extraction, and thin-layer chromatography $(T L C)$. Except where otherwise indicated, RBC were

1 New England Nuclear Corp., Boston, Mass. (lauric, myristic, palmitic, stearic), and Applied Science Laboratories, State College, $\mathrm{Pa}$. (linoleic).

2 Courtland Laboratories, Los Angeles, Calif. incubated at $37^{\circ} \mathrm{C}$ in buffer containing albumin, labeled fatty acid, and in most instances sufficient additional albumin so that the molar ratio of FFA to albumin and the FFA composition were not appreciably different from that of the original albumin. At the end of the incubation period, the cells were centrifuged and resuspended five times with approximately $10-\mathrm{ml}$ portions of isotonic saline. That this procedure removed the albumin was demonstrated by using ${ }^{125} \mathrm{I}$-labeled albumin as a tracer. (No ${ }^{125} \mathrm{I}$ radioactivity above background was detectable afterwards.) The erythrocyte lipids were then extracted into chloroform: methanol $(1: 1$, vol/vol) three times according to the method of Ways and Hanahan (9). Samples of the chloroform phase were evaporated to dryness and assayed for radioactivity by liquid scintillation counting. The remainder was evaporated to a small volume and analyzed by thin-layer chromatography on silica gel $\mathrm{G}$ plates using a solvent consisting of hexane, diethyl ether, methanol, and glacial acetic acid $(225: 50: 7: 5 \mathrm{vol} / \mathrm{vol})$. Standard lipids were chromatographed on each plate. In this TLC system, phospholipids remain at the origin, FFA migrate with an $R_{f}$ of about 0.6 , and cholesterol esters and triglycerides migrate close together with an $R_{\mathfrak{f}}$ of about 0.9 . The plates were sprayed lightly with $2^{\prime}-7^{\prime}$-dichlorofluorescein and examined under ultraviolet light. Only free cholesterol and phospholipids could be visualized. The regions corresponding to the phospholipid, FFA, and triglyceride of the standard were isolated and scraped off the plate. The remaining silica gel was then also scraped off. The radioactivity in the spot near the solvent front from three separate RBC incubations was clearly identified as triglyceride by chromatography in a less polar system. In subsequent analyses, this spot was analyzed without further subfractionation. The lipids were then eluted from the silica gel, the phospholipids with methanol and the FFA and triglycerides with chloroform. A sample of each eluate was evaporated to dryness and assayed for radioactivity by liquid scintillation counting at approximately $78 \%$ efficiency. From 80 to $90 \%$ of the radioactivity applied to the plate was recovered in the triglyceride, FFA, and phospholipid fractions. Each eluate was then evaporated to dryness, and the residue was incubated at $60^{\circ} \mathrm{C}$ for 16 to 20 hours with $2 \mathrm{ml}$ of $3 \%$ sulfuric acid in methanol (vol/vol) to convert the fatty acids to their methyl esters. After incubation, $2 \mathrm{ml}$ of water was added, and the methyl esters were extracted into light petroleum ether. ${ }^{3}$ The petroleum ether solution of methyl esters was then evaporated almost to dryness, and a portion consisting of most of the sample was injected into the GLC column.

3 The completeness of transesterification of the fatty acids in phospholipids by this procedure was studied by Whyte $(10)$. His results indicated that transesterification was essentially complete but that particular care had to be exercised in the extraction of the methyl esters derived from phospholipid from the aqueous methanol to ensure that extraction was quantitative. He found that all the long chain esters were equally affected. 
Because of the possibility of selective loss of unsaturated acids during TLC, care was taken to minimize the time that the lipids were permitted to remain on the TLC plate or on the silica gel exposed to air before they were eluted. Many analyses of mixtures of triglycerides and FFA before and after they were subjected to TLC with the procedures used here revealed no selective loss of linoleic or any other acid.

Gas-liquid chromatography. The methyl esters were analyzed by GLC at $190^{\circ} \mathrm{C}$ in a Packard model 801 gas chromatograph ${ }^{4}$ on coiled glass columns 6 feet long containing Chromosorb W coated with ethylene glycol succinate polyester, $12 \%$ by weight. The effluent of the column was split $6: 1$. The smaller fraction was directed to a hydrogen flame ionization detector, the larger to a combustion tube filled with cupric oxide, which was heated to $700^{\circ} \mathrm{C}$. The effluent of the combustion tube was passed through a tube containing magnesium perchlorate to remove water and then through either of two radiation detection systems. In the first, suitable quantities of additional argon, carbon dioxide, or both were added to make a total flow of $200 \mathrm{ml}$ per minute consisting of about $90 \%$ argon, $10 \%$ carbon dioxide. The combined gases were then passed through a 50-ml gas flow proportional counter with a thin window (Packard model 210 Flow Window Detector) ${ }^{4}(11,12)$. In the second, the effluent of the combustion tube was delivered to a flow-through anthracene crystal scintillation detector (Packard Flow Detector) ${ }^{4}(13)$. The counting rate was recorded on a strip chart recorder, and the distribution of radioactivity in the sample was calculated from the areas under the peaks of counting rate vs. time.

Plan of experiments. The effects of time of incubation, concentration of FFA, and addition of cofactors on the incorporation of fatty acids into RBC phospholipids and triglycerides were studied using palmitate- $-{ }^{14} \mathrm{C}$ as the only ${ }^{14} \mathrm{C}$-labeled tracer. The transfer of the various FFA from albumin to $\mathrm{RBC}$ and the incorporation of these acids into $\mathrm{RBC}$ lipids were studied by incubating the $\mathrm{RBC}$ with albumin to which a mixture of six ${ }^{14} \mathrm{C}-$ labeled acids was bound. In each of the latter experiments, the albumin-FFA both before and after incubation were extracted and analyzed at the same time as the $\mathrm{RBC}$ lipids. From the distribution of ${ }^{14} \mathrm{C}$ among the fatty acids of each lipid, the comparative or relative fractional uptakes of the different fatty acids from albumin-FFA or RBC-FFA, considered "precursors," into $\mathrm{RBC}$ phospholipids and triglycerides, considered "products," were calculated. The basis for these calculations was as follows. As in most experiments in which isotopes are used, it was assumed that the ${ }^{14} \mathrm{C}$-labeled acids were not distinguishable from their ${ }^{12} \mathrm{C}$ counterparts. The fractional incorporation or uptake of an acid in a time interval was then given by the ratio of ${ }^{14} \mathrm{C}$ in that fatty acid in the product to the ${ }^{14} \mathrm{C}$ in that fatty acid in the precursor. For comparing fractional uptakes, the contribution of each fatty acid to the total radioactivity in each product, in per cent, was divided by its con-

\footnotetext{
4 Packard Instrument Co., Downers Grove, Ill.
}

tribution in the precursor. These ratios were then "normalized" by dividing by the ratio for palmitic acid. The resulting numbers, the relative fractional uptakes, were thus derived solely from the distribution of radioactivity. The ${ }^{12} \mathrm{C}$ fatty acid composition of the precursor and product did not enter into the calculation. It will be shown that the relative fractional uptakes of different fatty acids did not vary when the ratios of the quantities of fatty acid present were changed. The usefulness of relative fractional uptakes as measures of the selectivity of the $\mathrm{RBC}$ for different fatty acids is based primarily on this observation.

\section{Results}

Time course of incorporation of fatty acid into phospholipids and triglycerides. When RBC were incubated with albumin to which ${ }^{14}$ carbon-labeled palmitate was bound, the radioactivity incorporated into phospholipids and into triglycerides increased steadily for 4 hours, after which further incorporation was minimal (Figure 1). In this experiment, the rate of incorporation of radioactivity into phospholipid was greater than into triglyceride; in others, the reverse was true. The quantity of ${ }^{14} \mathrm{C}$ in the $\mathrm{RBC}-\mathrm{FFA}$ fraction was the same in all samples taken.

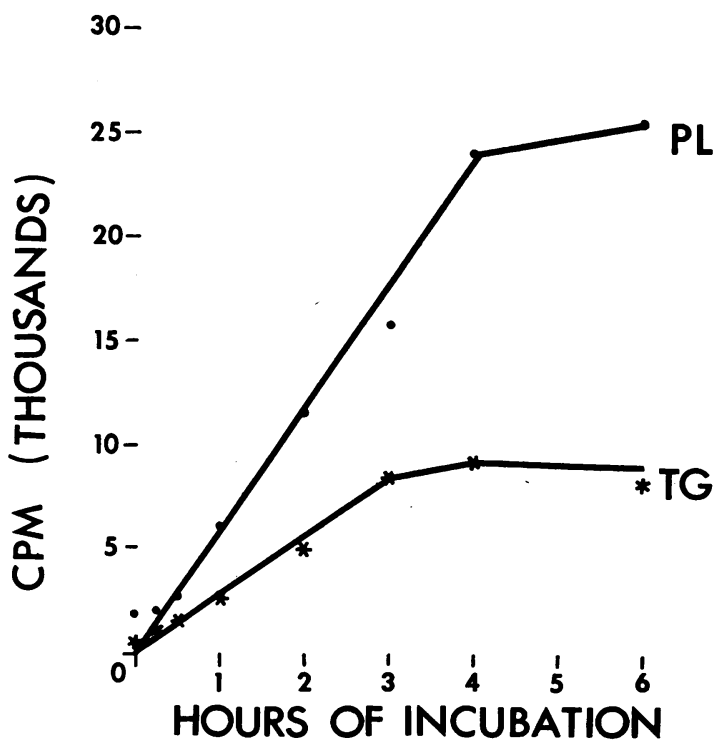

Fig. 1. Time course of incorporation of palmitate${ }^{14} \mathrm{C}$ INTO RED BLOOD CELL (RBC) PHOSPHOLIPIDS (PL) AND TRIGLYCERIDES (TG). The ordinate of the Figure is counts per minute per milliliter RBC. The incubation mixture consisted of $10 \mathrm{ml}$ washed RBC, $10 \mathrm{ml}$ buffer, $70 \mathrm{mg}$ albumin $(0.6 \mu$ mole FFA $)$, and $5 \mu \mathrm{c}\left(8.8 \times 10^{\circ}\right.$ $\mathrm{cpm})$ palmitic acid- ${ }^{14} \mathrm{C}$. The FFA fraction of each $\mathrm{RBC}$ sample contained $200,000 \mathrm{cpm}$ per $\mathrm{ml} \mathrm{RBC}$. 
TABLE I

Effect of glucose and cofactors on fatty acid incorporation into phospholipids (PL) and triglycerides (TG) in red blood cells $(R B C)$ stored in albumin overnight before incubation*

\begin{tabular}{|c|c|c|c|c|}
\hline \multirow{3}{*}{$\begin{array}{l}\text { Time of } \\
\text { incubation }\end{array}$} & \multicolumn{4}{|c|}{${ }^{14} \mathrm{C}$ incorporated } \\
\hline & \multicolumn{2}{|c|}{ Added nutrients } & \multicolumn{2}{|c|}{ No added nutrients } \\
\hline & PL & TG & PL & TG \\
\hline hours & \multicolumn{4}{|c|}{$c p m$} \\
\hline 1 & 786 & 207 & 600 & 131 \\
\hline 3 & 1,808 & 320 & 911 & 140 \\
\hline 5 & 4,183 & 508 & 2,209 & 136 \\
\hline
\end{tabular}

* Incubation mixtures contained $2.74 \times 10^{6} \mathrm{cpm}{ }^{14} \mathrm{C}$ labeled fatty acids (12:0, 14:0, 16:0, 18:0,18:1, 18:2), $50 \mathrm{mg}$ albumin, $4 \mathrm{ml}$ buffer, and $3 \mathrm{ml}$ washed RBC. In one mixture the buffer contained, in addition, $3 \mathrm{mg}$ glucose, $0.2 \mu$ mole coenzyme A, $2 \mu$ moles ATP, and 3 $\mu$ moles magnesium chloride (2).

Effect of glucose and cofactors on fatty acid incorporation into phospholipids and triglycerides. Freshly drawn $\mathrm{RBC}$ incorporated palmitate- ${ }^{14} \mathrm{C}$ into triglycerides and phospholipids at the same rate in mixtures containing added ATP, coenzyme A ( $\mathrm{CoA})$, magnesium chloride, and glucose as in buffer alone. RBC that had been stored in albumin and buffer at $5^{\circ}$ overnight before incubation incorporated more from the media containing the added nutrients. There was no detectable uptake into triglycerides by the stored cells unless these nutrients were added (Table I). Although the initial rate of ${ }^{14} \mathrm{C}$-labeled FFA incorporation into phospholipids was the same, after 1 hour the incorporation in the absence of nutrients was less.

Effect of concentration of free fatty acids on the
TABLE II

Effect of ratio of palmitic acid to albumin on the incorporation of palmitic acid into $R B C$ $T G$ and $P L$

\begin{tabular}{|c|c|c|c|c|}
\hline \multirow{2}{*}{$\begin{array}{l}\text { Incubation } \\
\text { mixture }\end{array}$} & \multirow{2}{*}{$\begin{array}{l}\text { FFA (16:0)/ } \\
55 \mathrm{mg} \text { albumin }\end{array}$} & \multicolumn{2}{|c|}{$\begin{array}{c}\begin{array}{c}\text { Palmitic acid } \\
\text { incorporated into: }\end{array} \\
\end{array}$} & \multirow[b]{2}{*}{$\mathrm{TG} / \mathrm{PL}$} \\
\hline & & TG & PL & \\
\hline & umoles & \multicolumn{2}{|c|}{ mumoles } & mumoles \\
\hline 1 & 0.2 & 0.8 & 0.7 & 1.1 \\
\hline 2 & 0.3 & 1.5 & 0.9 & 1.6 \\
\hline 3 & 0.7 & 3.8 & 1.8 & 2.1 \\
\hline 4 & 0.9 & 5.2 & 1.8 & 2.7 \\
\hline 5 & 1.2 & 7.4 & 2.4 & 3.0 \\
\hline 6 & 2.2 & 11.0 & 4.4 & 2.5 \\
\hline
\end{tabular}

incorporation into phospholipids and triglycerides. When the quantity of albumin in the incubation mixture was held constant, the micromoles of fatty acid incorporated into phospholipids and triglycerides increased with increase in the concentration of FFA on the albumin over the range from 0.2 to $2.2 \mu$ moles per $55 \mathrm{mg}$ albumin. With in crease in the molar ratio of FFA to albumin, incorporation into triglycerides was even more markedly increased than into phospholipids ( $\mathrm{Ta}$ ble II).

Uptake of different fatty acids into RBC phospholipids and triglycerides. At the end of 3 hours of incubation, in a typical experiment in which the ratio of albumin to $\mathrm{RBC}$ was low, one-fifth of the total radioactivity was associated with the cells and four-fifths was washed out with the albumin. Approximately $20 \%$ of the $\mathrm{RBC}$ radioactivity was in the triglyceride fraction, $12 \%$ in the phospho-

TABLE III

Fatty acid incorporation into RBC from albumin after 3 hours of incubation*

\begin{tabular}{|c|c|c|c|c|c|c|c|}
\hline \multirow[b]{3}{*}{ Total incubated after 3 hours } & \multirow{3}{*}{$\begin{array}{c}c p m \times 10^{-6} \\
5.25\end{array}$} & \multicolumn{6}{|c|}{ Distribution of ${ }^{14} \mathrm{C}$} \\
\hline & & \multicolumn{6}{|c|}{$\%$ of total } \\
\hline & & $12: 0$ & $14: 0$ & $16: 0$ & $18: 0$ & $18: 1$ & $18: 2$ \\
\hline $\begin{array}{l}\text { Albumin }(10.5 \mathrm{mg}) \\
\text { RBC total }(2 \mathrm{ml})\end{array}$ & $\begin{array}{l}4.20 \pm 0.15 \\
1.05 \pm 0.15\end{array}$ & 5.2 & 8.9 & 19.4 & 16.7 & 30.3 & 19.7 \\
\hline $\begin{array}{l}\text { RBC distribution } \\
\text { FFA }\end{array}$ & $\begin{array}{r}0.77 \pm 0.04 \\
(73 \pm 4 \%)\end{array}$ & $\begin{array}{r}3.0 \\
\pm 0.3\end{array}$ & $\begin{array}{r}8.2 \\
\pm 1.1\end{array}$ & $\begin{array}{r}22.1 \\
\pm 1.1\end{array}$ & $\begin{array}{r}45.8 \\
\pm 1.5\end{array}$ & $\begin{array}{r}17.4 \\
\pm 1.6\end{array}$ & $\begin{array}{r}3.1 \\
\pm 0.3\end{array}$ \\
\hline Triglyceride & $\begin{array}{r}0.19 \pm 0.04 \\
(18 \pm 4 \%)\end{array}$ & $\begin{array}{r}2.8 \\
\pm 0.3\end{array}$ & $\begin{aligned} & 10.0 \\
\pm & 1.1\end{aligned}$ & $\begin{array}{r}22.5 \\
\pm 3.0\end{array}$ & $\begin{array}{r}7.7 \\
\pm 0.5\end{array}$ & $\begin{array}{r}36.0 \\
\pm 2.0\end{array}$ & $\begin{aligned} & 21.4 \\
& \pm 2.2\end{aligned}$ \\
\hline Phospholipid & $\begin{array}{l}0.095 \pm 0.007 \\
(9.1 \% \pm 0.7 \%)\end{array}$ & 0 & $\begin{array}{r}5.5 \\
\pm 0.8\end{array}$ & $\begin{array}{r}27.1 \\
\pm 1.5\end{array}$ & $\begin{array}{r}9.7 \\
\pm 1.7\end{array}$ & $\begin{array}{r}38.6 \\
\pm 1.4\end{array}$ & $\begin{array}{r}19.7 \\
\pm 1.8\end{array}$ \\
\hline
\end{tabular}

* Each incubation mixture contained $2.0 \mathrm{ml}$ packed $\mathrm{RBC}$ and $3.0 \mathrm{ml}$ buffer containing $10.5 \mathrm{mg}$ albumin. The albumin contained $0.06 \mu$ mole FFA and $5.25 \times 10^{6} \mathrm{cpm}{ }^{14} \mathrm{C}$ (approximately $3 \mu \mathrm{c}$ ). The analyses are averages \pm standard deviations of results obtained by incubating RBC from three healthy subjects, each in duplicate. The numbers in parentheses below the mean and standard deviation are the percentages of the total counts in the RBC lipids. 
lipid, and the remainder, or almost $70 \%$, was free fatty acid (Table III). The distribution of ${ }^{14} \mathrm{C}$ among the fatty acids was different in the triglycerides, phospholipids, and FFA fractions of the red cells, and each, in turn, was different from the distribution in the FFA on the albumin. The total radioactivity and the distribution of radioactivity in each lipid were similar in each of the blood samples tested. This similarity is exemplified in the analyses shown in Figures 2 and 3. Comparison of the distribution of radioactivity among the FFA of the albumin and the RBC showed that larger fractions of free stearic and palmitic acids were associated with the RBC compared to oleic and linoleic. The distribution in the phospholipids and triglycerides was similar to that in the albumin-FFA except for less ${ }^{14} \mathrm{C}$ labeled stearic acid in phospholipids and triglycerides and the lack of uptake of ${ }^{14} \mathrm{C}$-labeled lauric acid into phospholipids (Table IV).

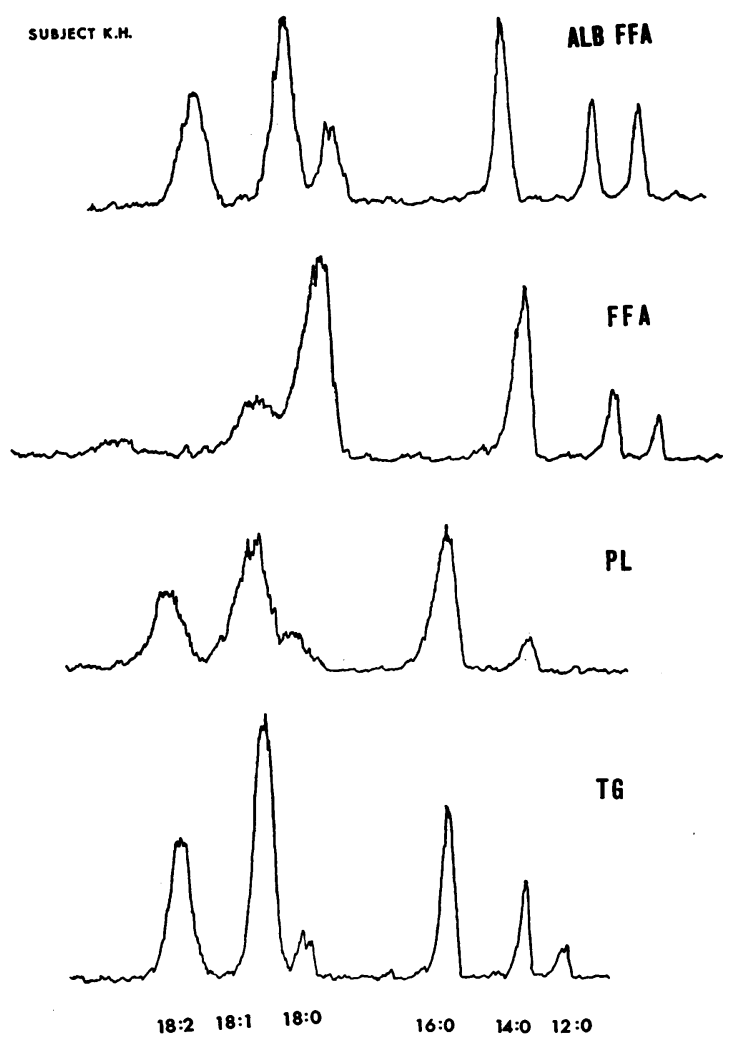

Fig. 2. Distribution by GAS-LIQUid ChROMATOGRAPHY (GLC) of ${ }^{14} \mathrm{C}$ among albumin FFA, RBC-FFA, RBC PHOSPHOLIPIDS, AND RBC TRIGLYCERIDES AFTER 3 HOURS OF INCUBATION OF RBC OF A NORMAL HUMAN SUBJECT WITH ALBUMIN.

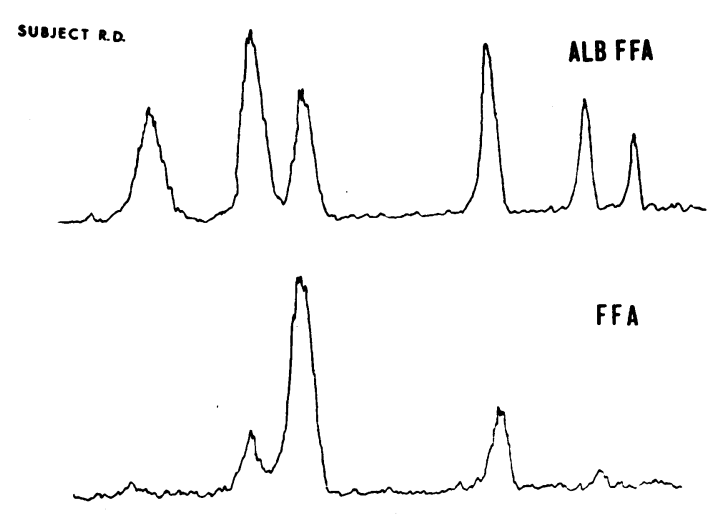

PL

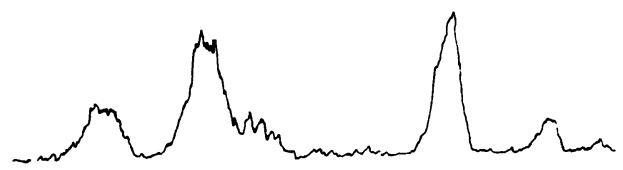

T6

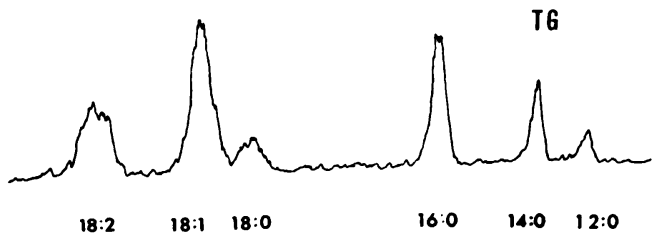

Fig. 3. Distribution by GLC of ${ }^{14} \mathrm{C}$ among albumin FFA, RBC-FFA, RBC PHOSPHolIPIDS, AND RBC TRIGLYCERIDES AFTER 3 HOURS OF INCUBATION OF RBC OF A SECOND NORMAL HUMAN SUBJECT WITH ALBUMIN.

Samples of incubation mixtures processed almost immediately after completion contained as much FFA associated with the RBC as those taken at the end of 6 hours of incubation.

TABLE IV

Relative fractional incorporation of fatty acids from albumin into $R B C$ lipids (relative to palmitate $=1.00)^{*}$

\begin{tabular}{lllllll}
\hline \hline & \multicolumn{6}{c}{ Fatty acid } \\
\cline { 2 - 7 } & $12: 0$ & $14: 0$ & $16: 0$ & $18: 0$ & $18: 1$ & $18: 2$ \\
\hline $\begin{array}{l}\text { RBC FFA } \\
\text { ALB FFA }\end{array}$ & 0.51 & 0.81 & 1.00 & 2.40 & 0.50 & 0.14 \\
$\begin{array}{l}\text { RBC TG } \\
\begin{array}{l}\text { ALB FFA } \\
\text { RBC PL }\end{array}\end{array}$ & 0.46 & 0.96 & 1.00 & 0.40 & 1.02 & 0.94 \\
$\frac{\text { ALB FFA }}{\text { ALB }}$ & 0 & 0.44 & 1.00 & 0.41 & 0.90 & 0.71
\end{tabular}

* Calculated from data presented in Table III. 
TABLE V

Independence of relative fractional uptakes of fatty acid composition*

\begin{tabular}{|c|c|c|c|c|c|c|}
\hline & \multicolumn{6}{|c|}{ Fatty acid } \\
\hline & $12: 0$ & $14: 0$ & $16: 0$ & $18: 0$ & $18: 1$ & $18: 2$ \\
\hline Albumin $\mathrm{I}{ }^{12} \mathrm{C} \%$ & 2.4 & 3.1 & 45.2 & 7.5 & 30.1 & 11.6 \\
\hline Albumin I ${ }^{14} \mathrm{C} \%$ & 2.5 & 1.9 & 25 & 16 & 35 & 19 \\
\hline Phospholipid I ${ }^{14} \mathrm{C} \%$ & 0 & 1.1 & 30 & 8.8 & 41 & 18 \\
\hline $\begin{array}{l}\text { Relative fractional uptake } \\
\text { from albumin I to } \\
\text { phospholipid I }\end{array}$ & 0 & 0.48 & 1.0 & 0.46 & 1.0 & 0.79 \\
\hline Albumin II ${ }^{12} \mathrm{C} \%$ & 2.2 & 3.5 & 31 & 5.7 & 38 & 20 \\
\hline Albumin II ${ }^{14} \mathrm{C} \%$ & 2.2 & 3.3 & 23 & 15 & 35 & 21 \\
\hline Phospholipid II ${ }^{14} \mathrm{C} \%$ & 0 & 1.9 & 26 & 10 & 39 & 23 \\
\hline $\begin{array}{l}\text { Relative fractional uptake } \\
\text { from albumin II to } \\
\text { phospholipid II }\end{array}$ & $\mathbf{0}$ & 0.51 & 1.00 & 0.59 & 0.98 & 0.97 \\
\hline
\end{tabular}

* Each tube contained albumin, $17 \mathrm{mg},{ }^{14} \mathrm{C}$-labeled FFA, $3.5 \times 10^{\circ}$ $\mathrm{cpm}$, and buffer, $3.0 \mathrm{ml}$, and was incubated for 3 hours.

Independence of relative fractional uptake of the composition of FFA on albumin. When the composition of the ${ }^{12} \mathrm{C}$-labeled FFA on the albumin (and on the RBC-FFA) was intentionally changed, the relationship between the distribution of ${ }^{14} \mathrm{C}$ in the $\mathrm{RBC}$ lipids and on the albumin was not significantly affected (Table V). We concluded that the relative fractional uptakes were independent of the relative concentrations of FFA present.

Transfer of $F F A$ from albumin to $R B C$. When solutions of albumin-FFA-14 $\mathrm{C}$ and of $\mathrm{RBC}$ were mixed together, the ${ }^{14} \mathrm{C}$-labeled FFA were distributed between the two in proportion to the relative quantities present. The ratio of ${ }^{14} \mathrm{C}$ per milligram albumin to ${ }^{14} \mathrm{C}$ per milliliter cells varied only from 1.7 to 0.9 as the albumin with its associated FFA was increased from 3 to $78 \mathrm{mg}$ per $\mathrm{ml}$ cells (Table VI). Approximately the same quantity of fatty acid was therefore associated with the cells. When the ratio of fatty acid to albumin was increased, correspondingly more fatty acid was associated with the cells. The RBC relative fractional uptakes of FFA from the albumin were not changed when the composition of the FFA was changed. Increasing the palmitic acid on the albumin from 20 to $70 \%$ of the total FFA did not change the distribution of radioactivity in the RBC-FFA fraction.

The rate of transfer of FFA from albumin to $\mathrm{RBC}$ was rapid. There was no more ${ }^{14} \mathrm{C}$-labeled
FFA associated with cells after 4 hours of incubation with albumin than after a brief exposure (about a minute) followed by dilution in $10 \mathrm{vol}$ of saline and centrifugation. Exactly how rapidly this transfer occurred could not be determined because of the time required to separate the albumin completely from the cells (about 10 minutes).

The FFA could also be removed from the RBC rapidly by suspending the FFA in albumin. Two $\mathrm{ml}$ of washed $\mathrm{RBC}$ was mixed with $1 \mathrm{ml}$ cold $\left(4^{\circ} \mathrm{C}\right)$ saline containing $12 \mathrm{mg}$ albumin to which a mixture of six ${ }^{14} \mathrm{C}$-labeled fatty acids was bound. The albumin was then removed by three times repeated centrifugation and resuspension in fresh cold saline. The RBC were then resuspended briefly in a new albumin solution containing its normal unlabeled FFA, but no ${ }^{14} \mathrm{C}$, after which this albumin was in turn removed. This entire process of resuspending the cells in albumin and then removing the albumin was repeated four times. Measurement of the radioactivity associated with the cells after each centrifugation revealed that most of the ${ }^{14} \mathrm{C}$ was removed in the first albumin solution. After four resuspensions in albumin, less than $1 \%$ of the added radioactivity remained associated with the cells.

The role of free fatty acid associated with $R B C$ in the incorporation of fatty acid into phospholipids and triglycerides. The uptake of labeled fatty acid into phospholipids and triglycerides was similar in cells exposed only momentarily to albumin-FFA${ }^{14} \mathrm{C}$, and then incubated in buffer, and in cells incubated in albumin-FFA- ${ }^{14} \mathrm{C}$ for the entire incubation period. Six $\mathrm{ml}$ of $\mathrm{RBC}$ was suspended in

TABLE VI

Effect of albumin concentration on immediate uptake of FFA (

\begin{tabular}{cccc}
\hline \hline $\mathrm{ALB} / \mathrm{RBC}$ & ${ }^{14 \mathrm{C} / \mathrm{RBC}}$ & ${ }^{14} \mathrm{C} / \mathrm{ALB}$ & $\mathrm{ALB} / \mathrm{RBC}$ \\
\hline$m g / m l$ & $\begin{array}{c}\text { cpm/ml } \\
\text { (thousands) }\end{array}$ & $\begin{array}{c}\text { cpm } / m g \\
\text { (thousands) }\end{array}$ & $\begin{array}{c}(\text { cpm } / m g) / \\
(\text { cpm } / m l)\end{array}$ \\
3 & 41 & 70 & 1.71 \\
8 & 19 & 31 & 1.63 \\
13 & 13.7 & 19 & 1.38 \\
18 & 11.5 & 14 & 1.22 \\
28 & 7.7 & 9 & 1.17 \\
53 & 5.0 & 5 & 1.0 \\
78 & 3.6 & 3 & 0.9
\end{tabular}

* Each incubation mixture consisted of $1.0 \mathrm{ml} \mathrm{RBC}$ and buffer containing albumin in the quantities shown in a total volume of $3.0 \mathrm{ml}$. The albumin in each instance contained approximately $0.006 \mu$ moles FFA per $\mathrm{mg}$. 
TABLE VII

Incorporation of ${ }^{14} C$-labeled fatty acid into $R B C$ phospholipids and triglycerides*

\begin{tabular}{ccc}
\hline & ALB present & ALB removed \\
\hline & cpm after incubation $($ thousands)/ \\
Experiment 1 & \multicolumn{2}{c}{} \\
RBC FFA & 612 & 480 \\
RBC PL & 80 & 76 \\
RBC TG & 101 & 39 \\
Experiment 2 & & \\
RBC FFA & & 754 \\
RBC PL & 717 & 78 \\
RBC TG & 88 & 125 \\
\hline
\end{tabular}

* Comparison of uptake when albumin was removed after 2 minutes and uptake when albumin was present throughout the 3-hour incubation period. In each experiment, the incubation mixture was prepared by suspending $6 \mathrm{ml}$ packed cells in $6 \mathrm{ml}$ buffer containing $35 \mathrm{mg}$ albumin and $22 \times 10^{6} \mathrm{cpm}{ }^{14} \mathrm{C}$-labeled fatty acids. The results above are analyses of 4-ml samples containing $2 \mathrm{ml} \mathrm{RBC}$.

buffered albumin to which a mixture of six labeled fatty acids was bound. After about 1 minute, three equal samples were removed and placed in separate tubes. The first was incubated as usual. The second and third were centrifuged, resuspended in saline, and recentrifuged to remove the albumin. Chloroform-methanol was then added to the second sample to extract the lipids. The third was incubated along with the first. At the end of 3 hours of incubation, similar quantities of ${ }^{14} \mathrm{C}$ were incorporated into phospholipids in the first and third tubes. Moderately less was

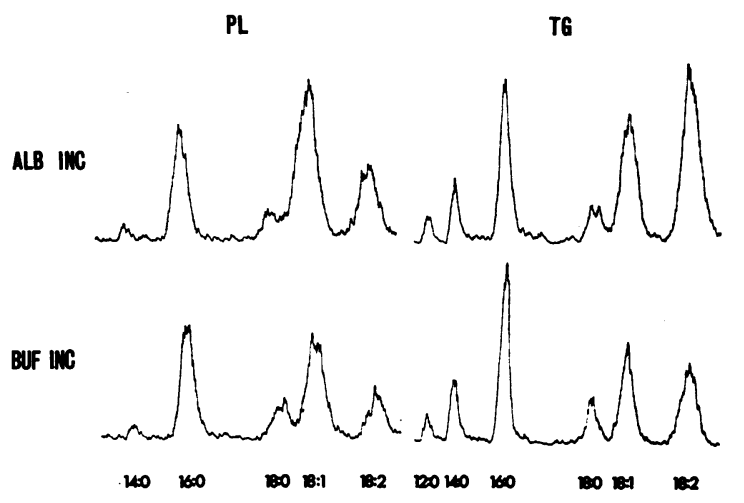

Fig. 4. Distribution of ${ }^{14} \mathrm{C}$ AMONG FATty ACIDS IN RBC TRIGLYCERIDES AND PHOSPHOLIPIDS WHEN CELLS WERE EXPOSED TO ALBUMIN BRIEFLY THEN INCUBATED IN BUFFER (BUF-INC) COMPARED TO THE DISTRIBUTION WHEN THE SAME CELLS WERE INCUBATED IN ALBUMIN FOR THE ENTIRE PERIOD (ALB-INC).

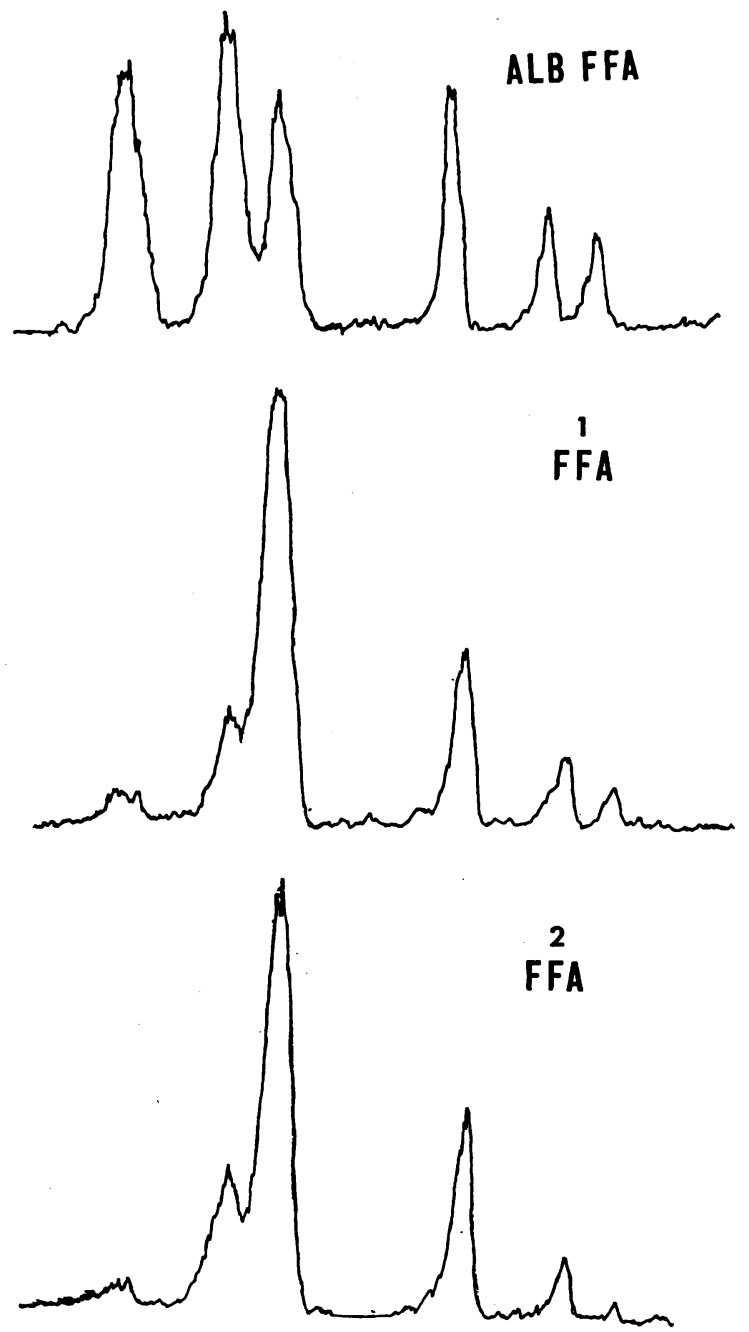

Fig. 5. Distribution by GLC of ${ }^{14} \mathrm{C}$ among FFA of ALBUMIN (ALB-FFA), FFA ON RBC AFTER EXPOSURE TO ALBUMIN FOR 1 MINUTE (1-FFA), AND 1-FFA INCUBATED FOR 4 HOURS IN BUFFER (2-FFA). The fatty acids are, right to left, $12: 0,14: 0,16: 0,18: 0,18: 1$, and $18: 2$.

incorporated into triglycerides in the mixture from which the albumin had been removed (Table VII). Distribution of ${ }^{14} \mathrm{C}$ among fatty acids of the phospholipids was also similar in both tubes, and there were only minor differences in the incorporation into triglycerides (Figure 4). The total ${ }^{14} \mathrm{C}$ and the distribution of ${ }^{14} \mathrm{C}$ in the $\mathrm{RBC}-$ FFA in all three tubes were also similar (Figure 5). These results indicated that the ${ }^{14} \mathrm{C}$-labeled fatty acids incorporated into RBC phospholipids and triglycerides during incubation could have 
TABLE VIII

Fractional incorporation of fatty acids from $R B C$-bound $F F A$ into $R B C$ lipid esters (relative to palmitate $=1.00)^{*}$

\begin{tabular}{|c|c|c|c|c|c|c|}
\hline & \multicolumn{6}{|c|}{ Fatty acid } \\
\hline & $12: 0$ & $14: 0$ & $16: 0$ & $18: 0$ & $18: 1$ & $18: 2$ \\
\hline$\frac{\mathrm{RBC} P L}{\mathrm{RBC} F F A}$ (from data in Table III) & 0 & 0.54 & 1.00 & 0.16 & 1.80 & 5.07 \\
\hline From total of 11 different blood samples & 0 & $\begin{array}{r}0.48 \\
\pm 0.15\end{array}$ & 1.00 & $\begin{array}{r}0.15 \\
\pm 0.02\end{array}$ & $\begin{array}{r}2.06 \\
\pm 0.75\end{array}$ & $\begin{array}{r}4.10 \\
\pm 1.27\end{array}$ \\
\hline$\frac{\mathrm{RBC} \text { TG }}{\mathrm{RBC} \text { FFA }}$ (from data in Table III) & .90 & 1.18 & 1.00 & 0.16 & 2.04 & 6.71 \\
\hline From total of 11 different blood samples & $\begin{array}{r}1.00 \\
\pm 0.79\end{array}$ & $\begin{array}{r}1.81 \\
\pm 1.01\end{array}$ & 1.00 & $\begin{array}{r}0.16 \\
\pm 0.05\end{array}$ & $\begin{array}{r}1.70 \\
\pm 0.69\end{array}$ & $\begin{array}{r}5.03 \\
\pm 2.60\end{array}$ \\
\hline
\end{tabular}

* The relative fractional uptakes and standard deviations thereof given here were means calculated from 11 different blood samples each analyzed in duplicate. The relative fractional uptakes calculated from the three samples in the experiment summarized in Table III, included in the 11, are presented for comparison.

come from (or through) the RBC-FFA fraction. On this basis, the relative fractional uptakes of the different fatty acids into triglycerides and phospholipids from the RBC-FFA were calculated. Fractional uptakes of linoleic and oleic acids from RBC-FFA were from two to seven times greater than those of palmitic, whereas those of stearic were only 0.15 as high. The fractional uptakes of lauric and myristic acids into triglycerides were approximately equal to that of palmitic. A smaller fraction of the myristic acid and none of the lauric were incorporated into phospholipid (Table VIII).

Comparative binding of various fatty acids to albumin. To estimate the relative affinities (8) of albumin for different fatty acids, a mixture of six fatty acids dissolved in $2 \mathrm{ml}$ heptane was carefully layered over $20 \mathrm{ml}$ phosphate-saline buffer, $\mathrm{pH} 7.35$, containing $70 \mathrm{mg}$ albumin. This was shaken gently in a Dubnoff shaker at room temperature for 36 hours, when most of the albumin solution was carefully removed from below the heptane. Most of the heptane (more than 90\%) was then removed and equilibrated with $40 \mathrm{ml}$ phosphate-saline buffer for 48 hours. The distribution of ${ }^{14} \mathrm{C}$ among the fatty acids in the albumin, saline, and heptane after its exposure to the albumin was then analyzed by GLC.

At this level of concentration of FFA on albumin, lauric and myristic acids were bound to albumin less strongly than palmitic, stearic, oleic, and linoleic acids. Oleic acid was most strongly bound (Table IX).

Studies of abnormal human $R B C$. FFA transfer from albumin to $R B C$ and incorporation of fatty acids into phospholipids and triglycerides were surveyed in blood samples from a few patients with a variety of diseases, including one each with primary hypercholesterolemia, congenital hemolytic anemia, abetalipoproteinemia, and Fabry's disease. RBC drawn from a normal individual were incubated at the same time with the same mixtures as the cells from each patient.

The transfer of FFA to $\mathrm{RBC}$ and their uptakes

TABLE IX

Comparative binding of fatty acids to albumin: distribution of FFA radioactivity in buffer in equilibrium with albumin-bound $F F A$

\begin{tabular}{|c|c|c|c|c|c|c|c|}
\hline & \multirow[b]{2}{*}{${ }^{14} \mathrm{C}$ total } & \multicolumn{6}{|c|}{${ }^{14} \mathrm{C}$ distribution } \\
\hline & & $12: 0$ & $14: 0$ & $16: 0$ & $18: 0$ & $18: 1$ & $18: 2$ \\
\hline & $c p m$ & \multicolumn{6}{|c|}{$\%$} \\
\hline Albumin & $38 \times 10^{6}$ & 11 & 10 & 19 & 16 & 27 & 17 \\
\hline Buffer & $42.7 \times 10^{3}$ & 35 & 29 & 10 & 8 & 10 & 9 \\
\hline$\frac{\text { Albumin/buffer }}{\text { Albumin 12:0/buffer 12:0 }}$ & & 1.0 & 1.0 & 5.8 & 7.0 & 9.9 & 6.4 \\
\hline
\end{tabular}


and relative fractional uptakes into triglycerides and phospholipids were similar to those in the control normal cells. The relative fractional uptake of linoleic acid into phospholipids and triglycerides in the RBC from the patient with abetalipoproteinemia was normal, even though the ${ }^{12} \mathrm{C}$-labeled linoleic acid was less than $1 \%$ of the fatty acids present.

\section{Discussion}

When human erythrocytes were shaken with serum albumin to which labeled FFA were bound, a fraction of the FFA was transferred to the cells. Although the precise rate of this transfer was too rapid to be measured by the technique employed here, there was no more ${ }^{14} \mathrm{C}$ in the RBC-FFA in the samples incubated for 4 hours than in the samples exposed only briefly to the albumin. The association of the FFA with the cells was reversible; the labeled acids could be removed completely by washing the cells several times with solutions of albumin. Increasing the concentration of a given acid on the albumin increased the quantity of that acid transferred to the cells proportionately. Increasing the ratio of albumin to cells increased the fraction of the total labeled acid that was bound to the albumin. It thus appeared that the FFA were distributed between the albumin and the $\mathrm{RBC}$ just as they might have been distributed between two immiscible solvents that were shaken together. The distribution coefficient, calculated as $\mathrm{FFA}-{ }^{14} \mathrm{C}$ per milligram albumin : $\mathrm{FFA}-{ }^{14} \mathrm{C}$ per milliliter $\mathrm{RBC}$, decreased by only one-half when the albumin was increased 25-fold. Each of the fatty acids was distributed between the albumin and the cells differently; the fraction of the stearate and palmitate associated with the cells at equilibrium was larger than the fraction of oleate and linoleate.

Goodman has reported that RBC bind FFA with affinities similar to those of the "second class" of binding sites of albumin (14). The results we obtained are not inconsistent with Goodman's model.

When the albumin and RBC were incubated together, the labeled fatty acids were slowly incorporated into cellular triglycerides and phospholipids. This reaction requires energy (2). Since addition of glucose, CoA, ATP, and magnesium ions had no effect on incorporation in freshly drawn erythrocytes, an adequate quantity of these nutrients was probably present. The requirement for these nutrients was more apparent in cells stored overnight and then incubated in buffer alone before the labeled acids were introduced.

The FFA esterified by the RBC were apparently first bound to the cells as FFA. The pattern and quantity of incorporation of ${ }^{14} \mathrm{C}$ when the cells were exposed to the albumin momentarily, removed, and then incubated in buffer were very similar to those when the cells were incubated in the presence of albumin.

Of three groups that measured uptakes of ${ }^{14} \mathrm{C}-$ labeled FFA into RBC phospholipids $(2,3,15)$, only Michaels, Wood, Mullin, and Kinsell also observed uptake into triglycerides. In our experiments, although there was very little triglyceride in the RBC samples, the identification of the lipid into which the ${ }^{14} \mathrm{C}$ was taken up as triglyceride is fairly sure. The retardation factor of the ${ }^{14} \mathrm{C}$ on TLC was the same as that of standard triglycerides. It was clearly separated from the FFA and from any of the other usual fatty acid-containing lipids. Its ${ }^{14} \mathrm{C}$ fatty acid composition was markedly different from that of the FFA fraction. The possibility was considered that it was a subfraction of the FFA isolated as an artifact of TLC. Against this was the fact that it was not present in samples taken from the mixture early in the incubation and that it increased slowly. Of all the parameters we measured, the quantity of ${ }^{14} \mathrm{C}$ incorporated into triglycerides was most sensitive to changes in the concentration of FFA, the length of time the cells were stored before incubation, the presence of nutrients, and the method of handling the cells. This sensitivity probably explains the different results obtained in different laboratories.

We also considered the possibility that the FFA were incorporated into triglycerides by the leukocytes remaining in the mixture rather than the RBC. However, Elsbach, in his studies of uptake of FFA by leukocytes (16), found that they incorporated fatty acids from albumin into phospholipids and triglycerides at almost the same rate. If we attribute the uptake of ${ }^{14} \mathrm{C}$ into triglycerides to leukocytes, we should also attribute at least some of the uptake into phospholipids to them as well. Unfortunately, our attempts to remove the 
leukocytes completely were not successful. There was, however, no correlation between the number remaining and the quantity of FFA incorporated into triglycerides. There was abundant uptake in mixtures containing as little as 300 to 400 leukocytes per $\mathrm{mm}^{3} \mathrm{RBC}$. On this basis, we tentatively concluded that the $\mathrm{RBC}$ were responsible for the triglyceride incorporation.

The relative fractional uptakes of the different FFA into RBC lipids did not change appreciably when the composition of the FFA pool was changed. It was therefore not necessary to use a precursor pool of equimolar or any other fixed composition to measure them. The albumin was therefore used with its complement of FFA as supplied or as altered by the addition of different quantities of labeled or unlabeled fatty acids.

The uptake of fatty acids into RBC triglycerides and phospholipids approximated a first-order reaction in the range of FFA concentrations used here (close to those the RBC and albumin would be exposed to in the circulating blood). In a first-order reaction, the relative fractional uptake is directly related to the rate constant. Relative fractional uptakes can also be measured by incubating individual albumin-bound ${ }^{14} \mathrm{C}$-labeled fatty acids with the $\mathrm{RBC}$ and comparing the uptakes of radioactivity. The advantages of measuring them by the method described here are that the radiochemical purity of the individual acids is somewhat less important and that each labeled acid serves in each separation step as an internal standard for the recovery of the rest.

Since the relative fractional uptakes are characteristic of the $\mathrm{RBC}$ rather than of a particular FFA pool, they are well suited for describing the selectivity of the RBC for different acids. Given the composition of the precursor FFA pool, the relative rates of uptake of different fatty acids can be predicted from the relative fractional uptake value. They thus may help in predicting how a change in the composition of the precursor pool may affect the composition of the RBC lipid.

Oliveira and Vaughan observed that the uptakes of oleic and linoleic acids into phospholipids of RBC ghosts were greater than those of the saturated acids and that all these acids were incorporated into the beta position of the lecithin. It was therefore tempting to try to explain the relatively high concentrations of unsaturated acids in the RBC phospholipids, particularly in the beta position, by this selectively higher incorporation. However, it is probable that the RBC in vivo are exposed to FFA bound to albumin, not FFA as free ions. As shown here, the fractional incorporation of the various fatty acids from albumin to $\mathrm{RBC}$ lipid esters does not vary greatly from one acid to another except for stearic acid. (This is in contradistinction to the fractional incorporation of RBC-FFA into the same lipids, which was different from one fatty acid to another.) One might therefore expect the beta position of the lecithin to resemble the FFA on the albumin. More experimental data are needed to clarify this point.

The uptake of fatty acids by the RBC offered a rather unique opportunity to dissect the process of FFA transport because of the rapid rate of transfer of FFA from albumin to cells and the relatively slow rate of incorporation of these acids into cellular lipids. In the studies of fatty acid incorporation into leukocytes described by Elsbach (16), the acids found in the cells were almost completely esterified into triglyceride. In the studies of fatty acid incorporation into ascites tumor cells reported by Spector and Steinberg (17), the quantity of fatty acid remaining as FFA was also small compared to that esterified into triglyceride, even early in the incubation period. We believe, however, that there are no marked differences in the pictures of fatty acid transfer and metabolism given by the studies of these different systems.

Our experiments indicated that the different fatty acids were all bound to albumin with about the same affinity, whereas Goodman (8) reported that linoleate was bound less strongly than some of the others. The relative affinities of the RBC varied much more. If other cells have the same relative affinities as the $\mathrm{RBC}$, the greater affinity for free stearic and palmitic acids could provide a mechanism by which unsaturated fatty acids, which seem to be incorporated into cellular lipids at a greater rate than the saturates once they reach the cells, are conserved in the bloodstream.

\section{References}

1. Farquhar, J. W., and E. H. Ahrens, Jr. Effects of dietary fats on human erythrocyte fatty acid patterns. J. clin. Invest. 1963, 42, 675. 
2. Oliveira, M. M., and M. Vaughan. Incorporation of fatty acids into phospholipids of erythrocyte membranes. J. Lipid Res. 1964, 5, 156.

3. Mulder, E., J. De Gier, and L. L. M. Van Deenen. Selective incorporation of fatty acids into phospholipids of mature red cells. Biochim. biophys. Acta (Amst.) 1963, 70, 94.

4. Mulder, E., and L. L. M. Van Deenen. Metabolism of red-cell lipids. Incorporation in vitro of fatty acids into phospholipids from mature erythrocytes. Biochim. biophys. Acta (Amst.) 1965, 106, 106.

5. Gordon, R. S., Jr., and A. Cherkes. Unesterified fatty acid in human blood plasma. J. clin. Invest. 1956, 35, 206.

6. Borgström, B. Investigation on lipid separation methods. Separation of cholesterol esters, glycerides and free fatty acids. Acta physiol. scand. 1952, 25, 111.

7. Hornstein, I., J. A. Alford, L. E. Elliott, and P. F. Crowe. Determination of free fatty acids in fat. Analyt. Chem. 1960, 32, 540.

8. Goodman, D. S. The interaction of human serum albumin with long-chain fatty acid anions. J. Amer. chem. Soc. 1958, 80, 3892.

9. Ways, P., and D. J. Hanahan. Characterization and quantification of red cell lipids in normal man. $\mathrm{J}$. Lipid Res. 1964, 5, 318.
10. Whyte, M., A. Karmen, and D. S. Goodman. Fatty acid esterification and chylomicron formation during fat absorption. II. Phospholipids. J. Lipid Res. 1963, 4, 322.

11. James, A. T., and E. A. Piper. Automatic recording of the radioactivity of zones eluted from the gasliquid chromatogram. J. chromatogr. 1961, 5, 265.

12. Karmen, A. Analysis of radioactive compounds by gas chromatography. J. Ass. off. agricul. Chem. 1964, 47, 15.

13. Karmen, A., I. McCaffrey, and R. L. Bowman. A flow-through method for scintillation counting of carbon-14 and tritium in gas-liquid chromatographic effluents. J. Lipid Res. 1962, 3, 372.

14. Goodman, D. S. The interaction of human erythrocytes with sodium palmitate. J. clin. Invest. 1958, 37, 1729.

15. Michaels, G., P. Wood, M. Mullin, and L. W. Kinsell. Lipid metabolism in human red blood cells. Fed. Proc. 1965, 24, 295.

16. Elsbach, P. Comparison of uptake of palmitic, stearic, oleic and linoleic acid by polymorphonuclear leukocytes. Biochim. biophys. Acta (Amst.) 1964, 84, 8.

17. Spector, A. A., and D. Steinberg. The utilization of unesterified palmitate by Ehrlich ascites tumor cells. J. biol. Chem. 1965, 240, 3747. 